\title{
The Paradox of Chocolate
}

\author{
Joseph Rego Daylyn Niren \& Shilpa Hinduja
}

"If any man has drunk a little too deeply from the cup of physical pleasure; if he has spent too much time at his desk that should have been spent asleep; if his fine spirits have become temporarily dulled; if he finds the air too damp, the minutes too slow, and the atmosphere too heavy to withstand; if he is obsessed by a fixed idea which bars him from any freedom of thought: if he is any of these poor creatures, we say, let him be given a good pint of amber-flavoured chocolate and marvels will be performed" - Anthelme Brillat-Savarin (1755-1826)

Scientifically proven to be a mood elevator due to its ability to promote serotonin in the brain, chocolate is popular for its aphrodisiac, relaxing, euphoric and stimulating characteristics. Renowned as a universally craved food, a majority of chocolate cravers, or chocoholics, have failed to find any close substitutes that can replace this divine invention (Parker, Parker and Brotchie, 2006). Chocolate holds the ability to transcend beyond merely a food, stimulating irrational behavioural tendencies within people even turning them into addicts.

The history of chocolate dates back to approximately 600 AD when the cocoa beans were discovered in the lowlands of south Yucatan in the Maya. It was initially consumed as a beverage known as chocolatl only by the emperors until it was developed as edible chocolate. Chocolatl had an unpleasant taste and its transformation to a desirable flavour is an interesting historical mystery.

Chemically, chocolate is composed of cocoa mass, cocoa butter and added sugar. Cocoa mass forms the base product which is obtained by processing the cocoa bean while cocoa butter is the natural fat from the cocoa bean which melts at room temperature to provide the creamy "melt in the mouth" sensation. Sugar was added as a primary ingredient by Europeans to appeal to their palate when chocolate was introduced from America (Parker, Parker and Brotchie, 2006). The present day chocolate industry is a mature and vibrant one consistently generating sales 
revenues of approximately 75 billion dollars annually and catering to consumers of all age groups (The Economist, 2008).

Production of the cocoa bean is primarily concentrated in West Africa, where Ghana, Nigeria and the Ivory Coast contribute approximately $70 \%$ of the world's supply (The Economist, 2008). These regions are well known for the quality of their beans due to the tropical climatic conditions they possess which are ideal for growing cocoa, making cocoa one of their key sources of foreign income. Often the opportunity cost of production is ignored as these regions primarily concentrate on cocoa trade overlooking other options for cultivation.

The Intertemporal Consumption Choice

The theory of rational addiction developed by Becker and Murphy explains strong addiction to a substance based, in part, on the effect past consumption has on current consumption (Becker and Murphy, 1988). By their definition, a person is a potential chocolate addict if the past consumption of chocolates increases the marginal utility of current consumption. The model also stresses the importance of 'unstable steady states', or a greater change in consumption levels when compared to the changes in other 'state variables' such as incomes and price levels, in analysing the behaviour of an addict. It suggests that the degree of addiction is strong when complimentarity between the past and current consumption is strong, and the degree of potential addiction raises the likelihood that the steady state is unstable which implies that consumption increases over time.

Rational choice theory helps in understanding the choices and behaviour of a chocolate addict. Ordinary rational consumers of chocolate, or any other good for that matter, maximize utility from stable preferences over time as they try to anticipate the future consequences of their choices. However, the behaviour of an addict, or a chocolate addict in our case, diverges from that of a rational consumer. 
This is because the rate at which the marginal utility for a chocolate addict diminishes is lower than that of a rational consumer of chocolate.

Theoretically, any addiction is characterised by an increased consumption over a shorter period of time with respect to the steady-state consumption levels of the substance being either stable or unstable. With respect to other relevant steady state factors, stable steady-state consumption is when consumption levels remain constant over time whereas an increase in consumption levels leads to an unstable steady state. However, small deviations from the consumption in an unstable steady state can cause major variations in the consumption pattern. This can lead to addiction since consumption at an unstable steady state can result in great cumulative rises over time.

According to the hyperbolic consumption model, preferences of individuals in the long-run tend to conflict with their short-run preferences. This model explains how the short-run preferences of individuals for instant gratification undermine their efforts to achieve patient long-run plans. Delaying gratification is a good long-term goal however instant gratification is extremely tempting. It states that, for hyperbolic discounters, delaying a short-run reward by a few days reduces the value of the reward more in percentage terms than delaying a long-run reward by a few days. Perhaps such consumers are more impatient while making decisions in the short- run compared to the long-run because they aim to maximise present utility more intensely. Therefore, ceteris paribus, individuals who discount the future heavily are more likely to resort to addiction. By this logic it is arguable that individuals who are present-oriented are more likely to be addicted to chocolates than more future-oriented individuals. Interestingly, a chocolate addict would react more strongly only to a permanent increase of the chocolate price rather than a temporary rise in the price. Naturally, there are also other determinants to the demand for chocolates like income and price levels or specific events where they might be an accompaniment to a celebration or even to ease temporary stress, all of 
which can independently stimulate the demand for chocolate and affect the level of addiction (Angeletos et al, 2001). All consumers experience a primary tension, between the desire to grab the rewards available in the present or trading off current consumption and being patient for a possibly larger future reward since it is a basal human tendency to succumb to instant gratification and a rational one to accumulate for a larger gain in the future (Lambert, 2006).

From Cocoa to Chocolate The irony of the story of chocolate is found in its production owing to the skewed distribution of income from the primary producer of the raw cocoa to the end manufacturer of chocolate. Due to unfair operating conditions, the farmers in Western Africa avail meagre wages from cocoa production compared to the wages paid to the manufacturers of chocolate (Tiffen, 2002). So minimal are the wage levels that some farmers are living on alarmingly dismal annual incomes of just 450 pounds (The Economist, 2008). Moreover, these farmers do not receive any recognition for cocoa production as chocolate companies refrain from having any direct association with them, failing even to feature cocoa origins on their packaging (Tiffen, 2002).

The cocoa market is akin to a perfectly competitive market since its produce is relatively homogeneous and is traded centrally in commodities exchanges. Not only do producers of cocoa lack market power or the ability to organise, they also lack any bargaining power in contracting with downstream producers. Additionally, producers of cocoa do not enjoy economic profits either due to relatively free entry for new farmers or other farmers that can switch to growing cocoa beans, which reduces the chances for existing farmers to maximise returns on their crops. This failure in the cocoa market has led to farmers engaging their own children to work in the farms rather than sending them to school. Some farmers have engaged in unfair and illegal practices such as trafficking of children across borders and 
forcing them to work under appalling conditions for 18-hour days, without adequate pay, housing, medical care, food and schooling in order to reduce costs (Tiffen, 2002). It is arguable that an increase in the revenues earned by farmers would help in solving this problem and prevent children from being exploited. However, achieving this by altering the production methods seems unlikely due to the absence of capital-intensive processes, the unavailability of technology, and the lack of know-how, all of which leaves farmers with little choice but to increase the price of cocoa to increase incomes, which is infeasible since they lack market power. So, while an increase in the quantity supplied of cocoa in the market would lead to an increase in revenues and a decrease in quantity supplied would push up the price and hence increase revenue these effects would only be possible if farmers in the cocoa market were able to coordinate their decisions.

Local merchants play a pivotal role in the production chain of chocolate by organizing and purchasing produce from farmers and selling it to trading houses who then resell to the eventual manufacturers of chocolate. Cocoa merchants and trading houses hereby earn their profits by playing the role of middlemen between the cocoa producers and the manufacturers of chocolate. The margins and terms of trade between all the parties in the cocoa-to-chocolate chain are not subject, at first sight, to the chocolate manufacturers' direct control, and rely on the local intermediaries that have the access to and relationships with farmers.

The chocolate industry, a monopolistically competitive market, provides a significant surplus to the few firms dominant in the market. Strategic marketing and advertising of differentiated products has made the chocolate industry a billion-dollar industry. However, there exists a significant bottleneck when it comes to a dispersion of these rents generated in the chocolate industry back to the cocoa farmer in the form of various trading houses, brokers and middlemen. An increase in consumer awareness of the plight of the farmer could lead to a demand for chocolate producers adopting more rigorous social responsibility standards in part 
by encouraging the adoption of best practices measures in their dealings with trading houses, a practise becoming popular in some sections of the coffee market. This could lay the much needed foundation for the process of chocolate production genuinely improving the lot of the cocoa farmers as well.

Due to the awareness of slave trade existing in Africa, firms have started working closely with organizations like the Fairtrade organisations. The price adjustment mechanisms ensured by Fairtrade organisations are aimed to protect small producers from volatile commodity markets that result from the freer trade and noholds-barred capitalism that multinational companies promote. They also provide them with contracts that allocate long term planning and social premiums that provide producers the ability to improve living and working conditions (The Economist, 2008).

The present scenario of cocoa production holds the potential of having an adverse effect on the demand for chocolate. However, chocolate manufacturers can address the issue by taking efforts to abolish the practices present thereby improving their image in society. At first, this may well just be a shift of some consumers to those brands that encourage fair trade, but, given time, could gradually encourage a larger industry-wide response. There are no free lunches in economics; producers and consumers will bear the brunt of increased costs initially but in the long run it is hard to deny that such as efforts would prove to be socially beneficial. Once the majority of the chocolate consumers are made aware of the real picture behind this sweet facade, chocolate can continue to be divine to enjoy without carrying with it the guilt of the exploitation. 


\section{References}

- Angeletos. G, Liabson. D, Repetto. A, Tobacman. J, Weinberg. S, 2001, The Hyperbolic Consumption Model: Calibration, Simulation, and Empirical Evaluation, retrieved on $15^{\text {th }}$ October 2008 from < http://www.jstor.org.ezproxy.deakin.edu.au/stable/2696556>

- Behrman. T. R, 1968, Monopolistic cocoa pricing, retrieved on $18^{\text {th }}$ November 2008 from< http://www.jstor.org.ezproxy-f.deakin.edu.au/stable/1238269 >

- Becker. G, Murphy. K, 1988, A Theory of Rational Addiction, retrieved on $30^{\text {th }}$ September 2008 from <http://www.jstor.org.ezproxy.deakin.edu.au/stable/1830469 >

- Lambert. C, 2006, The Marketplace of Perceptions, retrieved on $7^{\text {th }}$ October 2008 from<http://www.povertyactionlab.com/news/HarvardMagazine05.01.06.p $\mathrm{df}>$

- Parker. G, Parker. I, Brotchie. H, 2006, Mood state of effects of chocolate, Journal of Affective Disorders, retrieved on $11^{\text {th }}$ October 2008 from <http://som.flinders.edu.au/FUSA/GPEvidence/PHCRED/pdfs/chocolate.pdfs

- The Economist, 2008, Cocoa Farming Fair Enough, retrieved on $17^{\text {th }}$ October 2008 from

<http://www.economist.com/business/displaystory.cfm?story_id=10609020 $>$

- Tiffen. P, 2002, A Chocolate-Coated Case for Alternative International Business Models, retrieved on $21^{\text {st }}$ October 2008 from

- <http://www.jstor.org/stable/4029509> 